\title{
O DIREITO AMBIENTAL CONTEMPORÂNEO E A SUPERAÇÃO DA PERSPECTIVA ANTROPOCÊNTRICA
}

Evandro Borges Arantes 


\title{
O DIREITO AMBIENTAL CONTEMPORÂNEO E A SUPERAÇÃO DA PERSPECTIVA ANTROPOCÊNTRICA
}

\author{
Evandro Borges Arantes ${ }^{1}$
}

\section{RESUMO}

A maior atenção conferida hodiernamente ao tema ambiental não tem implicado necessariamente no enfrentamento adequado da questão, pois se reluta em superar a tradicional perspectiva antropocêntrica que, ao longo da civilização, foi vetor decisivo para o escasseamento dos recursos naturais do planeta. Por outro lado, também se reconhece a inviabilidade sócio-econômica do modelo oposto (ecocêntrico), razão pela qual este artigo discute a convergência desses paradigmas ambientais, defendendo uma terceira via que seja um "link" entre o pensar antropocêntrico e o pensar ecocêntrico, visto que só um modelo conjugado pode promover uma relação mais equilibrada entre o Homem e os demais elementos naturais que compõem o ecossistema global.

Palavras-chave: Direito ambiental, antropocentrismo, ecocentrismo.

\section{ABSTRACT}

The greater attention given to the environmental issue has not still involved necessarily appropriate coping in question, because if reluctant to overcome the traditional anthropocentric perspective

\footnotetext{
1 Professor Universitário e Consultor Jurídico. Graduado em Direito pela Universidade Estadual de Maringá (1999), com Pós-Graduação em Direito Administrativo e Constitucional pela Faculdade de Direito do Vale do Rio Doce (2004) e em Ciências Jurídico-Políticas pela Universidade Autônoma de Lisboa (2010). É Mestrando em Direito Público pela Universidade Autônoma de Lisboa. Foi Pró-Reitor de Administração e Finanças da Universidade do Tocantins - UNITINS e Chefe da Assessoria Jurídica da Secretaria de Estado da Educação e Cultura. Atualmente é professor titular da Faculdade Católica do Tocantins e Consultor Jurídico do Conselho Nacional de Secretários de Educação - CONSED, além de sócio do escritório Ferreira Borges Advogados Associados S.S. Ministra cursos, treinamentos e capacitações nas áreas de: licitações e contratos; lei de responsabilidade fiscal; parcerias público-privadas; procedimento disciplinar; direito administrativo e legislação educacional. E-mail: evandro@catolica-to.edu.br ou evandro@ferreiraborgesadvocacia.com.br. Fone: (63) 9994-3076.
} 
that, over the course of civilization, was decisive for the reduction of the planet's natural resources. On the other hand, also recognises the socio-economic infeasibility of opposite model (ecocentric), which is why this article discusses the convergence of these environmental paradigms, advocating a third way that is a "link" between the anthropocentric right thinking and the thinking ecocentric, as only a conjunction can promote a more balanced relationship between the human element and the other natural elements that make up the global ecosystem.

Keywords: Environmental law, anthropocentrism, ecocentrism.

\section{INTRODUÇÃO}

De tempos em tempos, notadamente após a divulgação dos resultados alarmantes de uma nova pesquisa auto intitulada "científica" ou do anúncio de mais uma palestra apocalíptica de alguma personalidade pública ávida pelo brilho sedutor dos holofotes, a discussão da temática ambiental ganha nova propulsão, embora, infelizmente, não raro essa discussão seja pautada pelo alarmismo panfletário que tem caracterizado a abordagem dos meios de comunicação de massa e, assim, obscurecido o debate ético sobre a conflitante relação/interrelação entre o Homem e o Ambiente em que vive.

Há, por conseguinte, um paradoxo que se estabelece na medida em que a recente massificação das informações sobre os riscos ambientais atuais e iminentes (o que deveria ser favorável ao enfrentamento do problema) culmina por dificultar a tomada de decisões que resultem em medidas econômica e cientificamente efetivas, já que o dimensionamento real dos 
problemas se desvirtua em meio às especulações, previsões $\mathrm{e}$ diagnósticos pouco ou nada consistentes em termos científicos, que atuam a serviço de interesses outros que não necessariamente a busca pelo desejável equilíbrio ambiental.

Não por acaso, há quem vislumbre no atualíssimo mote do aquecimento global uma oportunidade ímpar de fomentar um nicho em expansão do mercado editorial a quem interessa muito mais alarmar do que propriamente informar, Leis (2006), ou, o que é ainda pior, seria utilizado como subterfúgio para mitigar a soberania dos países subdesenvolvidos em relação aos seus recursos naturais, conforme $\mathrm{o}$ alerta seguinte:

O aquecimento global é um pretexto ideal para impor limites ao crescimento econômico dos países que ainda dispõem de riquezas naturais inexploradas (em geral pobres e/ou emergentes), bem como para legitimar a flexibilização de suas soberanias e a conseqüente internacionalização de suas reservas ambientais. (NAESS, 1989, p. 43):

Por conseguinte, nota-se que o Homem, ao longo de sua existência, além de ter se servido dos recursos naturais de forma predatória (já que sempre se auto-proclamou a razão única de todas as coisas e de todas as demais formas de vida) tem, hodiernamente, diante das mazelas ambientais a que ele mesmo deu causa, se colocado mais uma vez no centro da questão para, sob falso álibi preservacionista, obter dividendos mercadológicos com o próprio "enfrentamento" do problema posto, ou seja, a abordagem antropocêntrica da vida sobre a 
Terra, que foi determinante para a depleção (rebaixamento dos níveis de disponibilidade) dos recursos naturais, se faz presente também agora para propor (ou mesmo impor) medidas ditas "ambientalmente adequadas" para, supostamente, "salvaguardar a espécie humana".

Desta feita, a proposição do presente escrito é suscitar a discussão crítica acerca do antropocentrismo que, por razões históricas, culturais, religiosas, filosóficas, éticas etc. tradicionalmente tem norteado a práxis das relações entre o Homem e o Ambiente e se posicionado na essência epistemológica do Direito Ambiental.

Tal discussão intenciona, em última análise, por em foco a idéia contemporânea de superar a abordagem clássica do Direito Ambiental (antropocentrista), compatibilizando-a com uma visão mais Universalista ou, no dizer usual dos estudiosos do tema, com uma perspectiva Ecocêntrica que se assentaria basicamente na premissa de sustentabilidade:

Propõe a celebração da unidade homem-natureza, na origem e no destino comum, apontando para uma sensível mudança de paradigma que prescreve uma nova filosofia da raça humana como parte da natureza e sujeita às suas regras, substituindo a visão do homem afastado do restante do mundo natural e como seu senhor e dominador. (CAVALCANTI, 1999, p. 17)

Por outro lado, assim como o antropocentrismo "casto" se mostra anacrônico e, portanto, impróprio para uma discussão mais contemporânea sobre o Direito Ambiental, seria também 
impensável e contraproducente que aqui se pretendesse defender qualquer tipo de fundamentalismo ecocêntrico, até porque este artigo advoga em favor da idéia de que a retórica fundamentalista é nociva (e mesmo letal) em qualquer campo de análise científica.

Isto posto, faz-se imprescindível abordar as diversas variáveis ético-ideológicas afetas ao Direito Ambiental (supostamente antagônicas) buscando estabelecer interconexões entre elas, partindo-se da premissa de que é impossível sustentar empiricamente qualquer modelo puro, já que a existência de tais modelos puros se restringe às sistematizações teóricas, didaticamente formuladas de maneira compartimentada apenas para facilitar o estudo sinóptico de uma determinada área do conhecimento.

Por isso mesmo, a partir da análise que se seguirá nos capítulos subsequentes, (inicialmente estanque acerca das perspectivas antropocêntrica e ecocêntrica do ambiente) o presente artigo propõe justamente descompartimentar tais modelos, por defender que o suposto antagonismo entre ambos pode e deve ser superado a bem do desenvolvimento de uma terceira via ético-ambiental, conforme segue:

$\mathrm{Na}$ história do pensamento humano os desenvolvimentos mais fecundos ocorrem, de um modo geral, quando duas correntes totalmente distintas se encontram. Essas correntes podem radicar em zonas bastante diferentes da cultura humana, em tempos ou meios culturais diversos, ou até em diferentes tradições religiosas; assim, se de fato se chegam a encontrar, ou seja, se de fato são pelo menos aparentadas que uma verdadeira relação possa ter lugar, 
só se pode esperar que novos e estimulantes progressos se sigam. (HEISENBERG, apud CAPRA, 1989, p. 11):

\section{RELATO HISTÓRICO}

Certamente, à luz da contemporaneidade da presente propositura concernente à "superação do antropocentrismo", seria possível estabelecer como marco cronológico inicial deste estudo uma das convenções internacionais recentes que fizeram emergir a percepção de que a vida sobre a Terra não gravita ao redor do ego humano, como antes se pensava.

Todavia, para que as linhas deste trabalho tenham o êxito "descortinador" ora desejado, antes de avançar no tema específico (stricto), faz-se imprescindível voltar às origens históricas o quanto remotas possível do Direito Ambiental em seu sentido lato, pois não se pode conhecer o presente, sem se conhecer o passado, não se pode conhecer o que é, sem conhecer o que foi, como já alude a obra do insigne jurisconsulto Pontes de Miranda (1970).

A história da apropriação pelo Homem dos recursos naturais disponíveis no ambiente em que vive é tão antiga como a própria existência humana, sendo, obviamente, indispensável à própria sobrevivência da espécie, além de ter se constituído em elemento determinante do desenvolvimento sócio-econômico de todas as civilizações.

Porém, não obstante a inegável relação de íntima dependência, o relacionamento Homem/Ambiente sempre foi 
"de amor e ódio", na medida em que os domínios da natureza, apesar de fornecerem os meies essenciais à vida humana, representaram, ao mesmo tempo, uma barreira física que o Homem teve que transpor para estender seus domínios sobre o Território.

Por conseguinte, a idéia essencial que sempre marcou a relação do homo sapiens com o meio-ambiente nunca foi a de interdependência ou a de mutualismo simbiótico, pois a idéia prevalente sempre foi impor submissão a todas as demais espécies animais e vegetais (fauna e a flora) bem como vislumbrar todos os recursos da natureza (incluindo a atmosfera, as águas, os estuários, os elementos da biosfera, o mar, o solo e o subsolo) tão somente como reserva particular de suprimentos para satisfazer as necessidades humanas e de matéria-prima para suas criações, sendo que

"a concepção excessivamente antropocêntrica do Universo tem contribuído, provavelmente para que os seres humanos não reconheçam as outras criaturas e os recursos a não ser como um valor instrumental" (DÍAZ, 1.995, p. 17).

Assim, por milênios a fio, prevaleceu em quase todas as civilizações a concepção geral de que os recursos naturais e os demais seres viventes são propriedade da espécie humana, compondo o seu patrimônio (direito real), já que tais recursos eram "dádiva concedida por Deus ao Homem", ou seja, um "presente" do qual poderia ele usar, gozar, dispor e usufruir livremente, sem qualquer restrição. 
De igual forma, durante quase toda a história humana, difundiu-se a idéia de que os recursos naturais eram incomensuráveis e ilimitados e de que a exploração intensiva (ainda que desmedida) jamais seria capaz de esgotar a infindável generosidade da "mãe-natureza".

Vê-se, nesse contexto histórico, que ao fator ambiental é agregado um forte componente jusnaturalista ${ }^{2}$ (o direito ao ambiente como direito do Homem), considerando-se a apropriação da natureza pelo Homem como mais um direito dentre os que figuram como direitos naturais e, sendo assim, esse direito intrínseco se sobreporia a todas às normas positivadas, explicando, nessa ótica, o fato de que os textos normativos lançados recentemente em defesa do meio-ambiente têm tido muito pouco efeito prático.

Cabe pontuar que essa postura de "soberba" humana em relação ao meio-ambiente (de clara raiz romanística), manteve-se muito pouco suscetível a mudanças durante quase toda a cronologia histórica conhecida, tanto que, apenas com o avanço das telecomunicações, começou a emergir uma nova ideologia global, proporcionando o contato entre diversos povos e ampliando a visão do universo com a percepção da interdependência de relações entre os elementos da natureza.

Esses novos e irrefutáveis conhecimentos obrigam a espécie humana a reconhecer (mesmo que a contragosto) os

2 Referência à teoria do direito natural formulada por John Locke, segundo a qual existe uma categoria de valores inerentes a cada individuo desde o próprio momento da sua concepção (Direitos Naturais), como condição da sua existência plena e livre.

Revista Esmat, Palmas, Ano 3, n² 2, pag. 261 a 293 - jan/dez 2011 
direitos globais de todos os seres, o que, paulatinamente, foi sendo compreendido como: o direito à paz; o direito a um planeta desarmado; o direito de não matar e de não ser morto; o direito à não-violência; o direito à verdade, informação e educação; além do direito a um correto planejamento do futuro pelos governantes, direito este que se alargou com o tempo, passando a incluir também: o direito das gerações futuras; o direito a um planeta preservado; o direito de outras espécies; o direito à cidadania planetária e o direito a um correto relacionamento com a totalidade do universo, redundando, em termos atuais, no direito a viver em um ambiente ecologicamente equilibrado.

Também os anos 60 do século XX testemunharam uma abrupta mudança da consciência humana no que toca ao meioambiente, o que se deu em decorrência das catástrofes ecológicas que marcaram a época. Saliente-se, apenas para exemplificar, o histórico naufrágio do petroleiro Torrey Canyon que, em 13 de maio de 1967, causou um derramamento de petróleo sem precedentes, poluindo centenas de quilômetros das costas de França, Bélgica e Grã-Bretanha.

É assim que, nesse período, com o início do debate político e social sobre o ambiente, nasce o Direito Ambiental nos domínios das relações internacionais, já sob a ameaça de que o aumento da poluição e a deterioração dos valores naturais do planeta pudessem por em risco o mais primário dos direitos humanos: o direito à existência. Portanto, a tomada de consciência só se estabelece da relação de dependência direta entre a qualidade do ambiente e a vida humana, confirmando, 
com isso, a pertinência do adágio latino: ubi societas, ibi ius ${ }^{3}$.

O ano de 1968 é apontado como um marco no debate ambiental em virtude de ter vindo à lume uma resolução da Assembléia Geral das Nações Unidas, na qual se exprime inquietação no concernente às mudanças súbitas do meio sobre a condição do homem. Nesse mesmo ano, assiste-se à convocação da Conferência das Nações Unidas sobre o Ambiente Humano na sequencia da Conferência Internacional dos Direitos do Homem (Teerã, 1968), onde já se apelava (embora ainda como simples retórica) a um equilíbrio entre o progresso técnico-científico; a elevação intelectual, cultural e moral da humanidade; e a preservação ambiental, tanto que a própria Assembléia da ONU chamou à atenção para a interdependência entre a proteção do ambiente e os direitos do homem. Contudo, nota-se que , tais iniciativas, embora muito importantes, estavam todas evidentemente marinadas com um forte tempero antropocêntrico (com as devidas escusas pelo uso da metáfora gastronômica).

Já nos idos do ano de 1972 ocorre a primeira grande ação, em escala planetária, sobre o Ambiente (a Conferência de Estocolmo sobre a proteção do ambiente humano), da qual resultou o Programa das Nações Unidas para o Ambiente. Sabese, contudo, que a Declaração de Estocolmo não tem força de lei, mas sua significância decorre do fato de ela constituir uma interpretação de direito do homem que figura na Carta das Nações Unidas. Além disso, tal declaração forneceu motivação

3. Tradução: Só quando encontra o problema é que a sociedade sente a necessidade de uma resposta organizada.

Revista Esmat, Palmas, Ano 3, n² 2, pag. 261 a 293 - jan/dez 2011 
filosófica e jurídica à elaboração do Direito Ambiental.

É na conferência da Suécia que se inaugura o imperativo da utilização racional dos recursos naturais, como forma de evitar que a exploração excessiva e irracional traga malefícios que afetem a capacidade produtiva da terra e, com isso, ponha em risco a sobrevivência humana. Tal imperativo responsabiliza os governos pela preservação e melhoria do ambiente, salientando o primado do Estado em matéria de gestão dos recursos ambientais, a par de uma obrigação de cooperação com vistas a prevenir ou atenuar os malefícios que degradam o ambiente para além das suas fronteiras.

Vê-se aí o embrião ideológico dos valores que mais tarde vieram a ser denominados Princípio 21, que tem sido uma bandeira fundamental do ambientalismo atual, por proclamar o direito soberano dos Estados para explorar os seus recursos, desde que assegurem que as atividades sob sua jurisdição não causem danos ao ambiente de outros Estados para além de suas fronteiras. Aliás, tal princípio é novamente reforçado quando da realização da ECO 92 (Conferência do Rio de Janeiro, 1992), a partir de onde passou a ser mais usualmente conhecido como Agenda 21.

Por certo, após essas primeiras grandes reuniões planetárias acerca do mote ambiental, pode-se afirmar o início de um novo tempo, em que se confere ao maio-ambiente dignidade e altivez constitucional, embora em muitos países se tenha, diante disso, reforçado ainda mais o matiz antropocêntrico do tema, visto ter sido todo o ambiente terrestre "promovido" (ou 
reduzido) ao status de direito fundamental do cidadão.

Não obstante essa discussão paradigmática, essencial é lembrar que a essa altura já despontam os primeiros conceitos, institutos e instrumentos próprios dessa área do direito, tais como: o conceito de "dano ecológico" e a figura do "Estudo de Impacto Ambiental", abrindo-se caminho para que, mais adiante, se chegasse à formulação do princípio do poluidorpagador; princípio da participação e do não menos importante princípio da prevenção.

Cabe destacar ainda que, após Estocolmo (1972), sucederam-se outras importantes convenções, ratificadas por um número cada vez maior de países, destacando-se: Convenção para a preservação da poluição marinha por despejo de resíduos e outras matérias (Londres, 1972); Convenção Internacional para a prevenção de poluição causada por navios (Londres, 1973); Convenção sobre o comércio internacional de espécies ameaçadas da fauna selvagem e da flora (Washington, 1973); Convenção sobre a proteção do ambiente marinho na área do Mar Báltico (1974); Tratado sobre poluição transfronteiriça a longa distância (Genebra, 1979); e Convenção sobre a conservação da Vida Selvagem e dos Habitats Naturais (Berna, 1979).

Também não há como deixar de mencionar a importância da série de eventos iniciada com a Toronto Conference on the Changing Atmosphere (Canadá, outubro de 1988), seguida pelo IPCC's First Assessment Report (Sundsvall, Suécia, agosto de 1990) e que culminou com a Convenção-Quadro das Nações Unidas sobre a Mudança Climática, formalizada na já 
mencionada Conferência do Rio (ECO 92).

Apenas para ilustrar a proporção que a temática ambiental ganhou atualmente em termos de importância, cabe registro de que a ECO 92 é, ainda hoje, o maior encontro de Chefes de Estado e/ou de Chefes de Governo de que se tem notícia na história, visto que mais de cento e sessenta governos assinam a Convenção Marco sobre Mudança Climática, cujo objetivo central era evitar interferências antropogênicas perigosas no sistema climático.

Insta ressaltar que o objetivo acima transcrito é sintomático em termos de mudança de perspectiva do ambiente, posto que, ao considerar perigosas as interferências antropogênicas, se está a retirar enfim o Homem do pólo passivo da relação com os danos ambientais, ou seja, o homem deixa de ter o papel tradicional de "vítima potencial" do desequilíbrio ambiental.

Esses e outros efeitos daECO 92 continuaram repercutindo nos anos subsequentes, tanto que dez anos depois, no que se denominou $\mathrm{RIO}+10$, houve uma importante reavaliação da atuação dos Estados em prol dos objetivos traçados pela Agenda 21, haja vista a realização da Cimeira sobre o Desenvolvimento Sustentável (Johanesburgo, agosto de 2002).

Por fim, não caberia encerrar a questão sem referência ao Protocolo de Kyoto (1997) ${ }^{4}$, que se constitui em um tratado resultante de uma conferência sobre mudanças climáticas

\footnotetext{
4 Embora assinado em 1997, o Protocolo de Kyoto só foi implementado de fato em 2004 com a adesão da Rússia (então $2^{\circ}$ maior emissor dos gases causadores do efeito estufa), atingindo assim de $55 \%$ dos países poluentes.
} 
ocorrida na oportunidade. O documento propõe estabelecer metas de redução das emissões de gás carbônico, ou, mais precisamente, comparando-se com os níveis encontrados no ano de 1990, reduzir os níveis mundiais de emissão de gases do efeito estufa em 5,2\%, até 2012.

É notório que a meta estabelecida (que a bem do Planeta deveria ser ainda maior) acaba por ser considerada audaciosa ou inatingível, na medida em que os maiores emissores de gases (os Estados Unidos, responsáveis por mais de 35\% das emissões) se negaram a subscrever o acordo, valendo-se do pretenso argumento de que cumprir com a meta implicaria em "frear o crescimento econômico do país".

É interessante perceber que o revés imposto pelos norteamericanos ao ambientalismo global, muito mais do que um simples ato de suposta "arrogância típica" é um indicativo de que, além do antropocentrismo (até então visto como o único contraponto ao avanço do Direito Ambiental), haveria outra perspectiva de mundo ainda mais danosa em termos de concepção de vida, que seria o "economicentrismo", característico de uma ideologia capitalista levada às últimas conseqüências.

Ou seja, nessa perspectiva, os fatores econômicos (produção industrial; mercado financeiro; relações comerciais; etc.) passam a ser um fim em si mesmo e não um elemento acessório do desenvolvimento da sociedade. O poder do capital privado e a busca incessante pelo crescimento da economia nacional passam a ocupar o centro do Universo e das atenções, tornando-se fatores preponderantes (critérios balizadores) das 
decisões acerca da adoção ou não das medidas ambientais corretivas, que os seres viventes do Planeta estão a requerer com urgência e prioridade.

\section{ACONCEPÇÃO ANTROPOCÊNTRICADO AMBIENTE}

Etimologicamente, o termo antropocentrismo é um vocábulo híbrido de composição greco-latina, que conjuga, do grego, anthropos (ser humano) com, do latim, centricum (o centro). Assim, o pensamento antropocêntrico (que assim como o termo foi cunhado na filosofia clássica) coloca a espécie humana no centro do universo, em cujo redor gravitam todos os demais seres, em papel subserviente.

Destarte, a abordagem antropocêntrica é, sobretudo, utilitarista, na medida em que parte do pressuposto de que é necessário proteger a natureza apenas e tão somente para que os desequilíbrios ambientais não provoquem efeitos colaterais que porventura possam ameaçar a sobrevivência humana. Inexistem, portanto, quaisquer motivações altruístas e/ou de respeito pelas demais espécies.

Nessa visão, a verdade que se revela acerca do convívio Homem/Ambiente é a de que os Homens têm direito a serem protegidos também através da proteção do seu ambiente (KISS, 1989), considerando que o ambiente que circunda o Homem é talvez o "meio" mais importante que lhe consente viver com dignidade e bem estar e, assim, exprimir a sua própria personalidade. 
Assim, uma das principais características da acepção antropocêntrica do Universo é a crescente preocupação normativa em relação a tudo o que se constitui em iminente prejuízo para a saúde e para o bem estar humano. De tal forma, poder-se-ia definir como o primado da visão antropocêntrica a frase que, sob a proteção de sua aparente ingenuidade politicamente correta, encarna bem a idéia: "ferindo a natureza o homem está se ferindo também".

$\mathrm{Na}$ aludida concepção, não se nega que o Homem seja parte da natureza, mas, por outro lado, não se admite que ele seja uma parte agregada qualquer ou apenas mais um dos integrantes do ecossistema. Ele é indiscutivelmente considerado o centro do universo e possuidor de um magnetismo natural que faz com que todas as componentes naturais que se encontram presentes tanto na biosfera, como também na atmosfera, na hidrosfera e na litosfera gravitem ao seu redor, servindo-o.

Não é difícil identificar, nesse modelo, determinadas características inspiradas nas correntes do modernismo do século XIX. Ele parte de pressupostos mecanicistas incutidos pela perspectiva cartesiana, assume contornos analíticos onde não só subentende que é possível conhecer para controlar e subordinar o mundo natural aos caprichos humanos como se alvitra a fazer desse o seu principal objetivo.

Por isso, há quem diga que o antropocentrismo é a via de entrada do ambientalismô realista, à medida que se apresenta compatível com os valores dominantes. Aqui, é o próprio interesse egoísta humano que o faz preocupar-se com a proteção 
ambiental.

Trata-se, no dizer de seuś inúmeros críticos, de uma acepção anti-ecologista que se assenta, presunçosamente, nos princípios seguintes: a) superioridade humana e domínio sobre as outras espécies; b) crença no progresso tecnológico para resolução de quaisquer problemas; c) existência de recursos ilimitados; d) as pessoas como donas do seu destino, podendo escolher os seus objetivos, e alcançá-los de maneira livre.

Partindo-se de uma perspectiva histórica abrangente, seguindo a ainda pertinente linha central da antiga Grécia, é possível pontuar que a matriz filosófica clássica é pautada na visão antropocêntrica do Universo, haja vista que desde Protágoras (480-410 a.C) já se proclamava a idéia estruturante do antropocentrismo: "O Homem é (ou deve ser) a medida de todas as coisas" no que, obviamente, incluía todos os componentes ambientais, sendo que tal idéia perpassa também por Aristóteles (384-322 a.C) e, bem mais adiante, por Santo Tomás de Aquino (1225-1274), que deram alicerce à tese de que o Homem está situado no vértice de uma pirâmide natural, em que os minerais (na base) servem aos vegetais, os vegetais servem aos animais que, por sua vez, e em conjunto com os demais seres, servem ao Homem.

Essa construção perpassa também pela concepção romanista do homem caçador, dono da terra e dos seus recursos. Assim, por meio de um considerável esforço de síntese, é possível dizer que em uma postura antropocêntrica a natureza é sempre circunscrita a um meio para garantir a satisfação 
das necessidades humanas, já que a tese central utilizada é a necessidade pragmática de proteger a natureza apenas porque ela assegura as condições de existência do ser humano, e não pelo valor intrínseco do direito à vida. Portanto, as formas de vida encontradas na natureza aparecem destituídas de valor intrínseco; elas só adquirirão valoração quando cumprirem algum papel decisivo para a manutenção da qualidade de vida do ser humano, obtendo valor meramente instrumental.

Há, ainda, uma componente religiosa muito marcante, visto que a tradição judaico-cristã, que molda o Ocidente dentro dessa visão do Homem como a razão de ser de todas as coisas, assentou seus dogmas na mais pura concepção antropocêntrica, o que fica muito claro, inclusive, em diversas passagens bíblicas, a exemplo do que ocorre no versículo 28 do capítulo $2^{\circ}$ do Livro de Gênesis: "Crescei e multiplicai-vos e enchei a Terra,e subjugai, e dominai (...)". A própria construção bíblica da "criação do Homem à imagem e semelhança de Deus" acentua a prevalência humana sobre as demais espécies; o que também se verifica pela aventada intenção divina de "criar o Paraíso para dá-lo de presente ao Homem"; ou, ainda, quando exalta a virtuosidade dos que, em seus rituais de fé, submetiam animais (carneiros, ovelhas etc.) à sacrifícios físicos e à própria morte.

Assim, interpretando-se o mote ambientalista à luz de uma construção ideológica- filosófico-religiosa, há que situá-lo necessariamente no terrenô dos valores culturais, paradigmas e visões de mundo, que desde o surgimento do monoteísmo, moldaram na espécie humana o antropocentrismo e todos os 
seus valores filosóficos (cristianismo; cartesianismo; dualismo; utilitarismo; racionalismo; mecanicismo; materialismo; individualismo, etc.).

Não por acaso, na origem do pensamento ambientalista, vislumbra-se a dicotomia havida entre o ecocentrismo e o antropocentrismo, que seria um equivalente ideal do enfrentamento das forças sustentabilistas versus as forças desenvolvimentistas (que também num primeiro momento eram excludentes), mas que logo depois passaram a compartilhar certas vias de convergência, fusionando-se, criando um antropocentrismo relativizado pela crise ambiental.

A vertente ambientalista que se julga atual, de cunho ecocêntrico extremado, muniu-se de farta adjetivação (nada elogiosa) para referir-se à visão ambiental antropocêntrica como sendo Determinista; Mercantilista; Capitalista; Mecanicista; Cartesiana; e Provinciana.

Não bastasse isso, os precursores desse ecocentrismo radical (que de forma sectária se contrapuseram ao antropocentrismo), batizaram a vertente antropocêntrica de Ecologia Superficial (Shallow Ecology), por entender que tal vertente só se desenvolveu por motivações utilitaristas, em razão de certa apreensão com a sobrevivência humana ante a possibilidade de uma catastrófica crise ambiental absoluta e irreversível (NAESS, 1989).

Por sua vez, os novos arautos do antropocentrismo (os economistas ambientais) acabam por confirmar que, de fato, estão acomodados no seio da tal Ecologia Superficial, visto que, 
com suas teses, buscam evidenciar de que forma os "serviços da natureza" são úteis para a qualidade de vida humana, justificando a proteção ambiental não pelo seu valor intrínseco, mas como uma fonte de recursos em termos de oferta de produtos e serviços.

Vê-se, destarte, que à natureza é atribuído valor apenas utilitarista e instrumental, e sua proteção se deve unicamente ao seu aproveitamento em benefício do ser humano, esse entendido como o ápice da evolução.

Recentemente, mesmo os maiores expoentes antropocentristas vêm propondo uma mudança reformista, por intermédio da inclusão da dimensão ecológica na vida social, basicamente através da racionalidade econômica que agora pode corrigir as falhas de mercado da economia, passando a incorporar as externalidades ambientais, desde que, obviamente, a contabilidade ambiental apresse-se a valorar a natureza.

No Brasil, ninguém menos do que o professor Miguel Reale, cujo mérito é incontestavelmente reconhecido, assinala o primado absoluto dos valores humanos, pois, segundo o autor a ecologia subordina-se à antropologia e a pessoa humana é a fonte de todos os valores individuais e coletivos (REALE, 2005), defende ele, neste particular, certos valores que denomina invariantes axiológicas, exemplificando-as com o valor da pessoa humana, o direito à vida e à liberdade, negando, portanto, ao ecológico um valor absoluto, reduzindo-lhe o papel e a importância na medida êm que é apenas subsidiário da vida humana. 


\section{A CONCEPÇÃO ECOCÊNTRICA}

Apenas por rigor metodológico, incumbe ressaltar que, etimologicamente, o termo ecocêntrico também é uma conjugação greco-latina, em cujo centricum (centro) das atenções passa a pertencer à eco (vida em sentido lato) e não mais apenas ao Homem.

Assim, a concepção ambiental ecocêntrica foi moldada hodiernamente como um contraponto ao utilitarismo antropocêntrico, propondo a superação dos ideais clássicos (cartesianos) do monopólio valorativo até então conferido à espécie humana, de forma a considerar que a expansão do ecologismo expressa um ressurgimento ético que tenta evadir-se da postura individualista e antropocêntrica para atingir postura mais coletiva e biocêntrica (LEIS e D'AMATO, 1995).

Essa concepção ecocêntrica, fulcrada na cosmovisão da ética planetária, se auto-proclama sócio-construtivista; social; holística; interpretativa e crítica, buscando, com isso, posicionarse diametralmente oposta à ética antropocentrista, defendendo que todas as preocupações científicas, políticas, econômicas e culturais passem a ser centradas na "Oikos" (a Terra considerada como a casa comum de todas as espécies e como um sistema/ organismo vivo), conforme prescrito pela Teoria de Gaia ${ }^{5}$.

\footnotetext{
5 A Teoria de Gaia (nome da antiga deusa grega pré-helênica que simbolizava a Terra viva) pressupõe que o Planeta Terra é um sistema complexo que forma um todo orgânico, vivo, possuindo características próprias, homeostáticas e dinâmicas enquanto conjunto, apresentando características próprias que escapam às qualidades e atributos de cada uma de suas partes e/ou espécies constituintes.
} 
Segundo esse novo olhar para o ambiente, o mundo natural tem seu valor próprio, inalienável e intrínseco (isto é, tem um valor independente da experiência ou das preferências humanas), uma vez que ele é muito anterior ao aparecimento do homem sobre a Terra. $\mathrm{O}$ meio ambiente passa a ser entendido numa realidade complexa composta por seres animados e inanimados que existem e se relacionam entre si, em processo ininterrupto de interações, formando uma rede ou cadeia.

Como se pode supor, a concepção ecocêntrica do meio ambiente é bastante influenciada por tradições culturais, religiosas, filosóficas e éticas do mundo oriental, de onde emerge um humanismo universal que transcende o paradigma antropocêntrico e promove o desenvolvimento de sociedades que se sustentam no reconhecimento da importância de cada ser vivente e do protagonismo compartilhado entre as espécies, valorizando o conhecimento científico que se constrói nessa perspectiva.

Assim, a ética religiosa oriental (notadamente a budista) não atribui à humanidade um papel de superioridade e domínio em relação às outras espécies. Pelo contrário, à semelhança dos defensores da perspectiva gaiana da Terra, tal ética atribui à espécie humana um papel igualitário em relação às restante espécies, inseridas num ecossistema global, cujas qualidades particulares, como a razão e a consciência, ao invés de lhe atribuírem direitos de exploração, a responsabilizam pelo zelo e bem-estar de Gaia.

Curiosamente essa ética oriental ecocêntrica tem 
ultrapassado fronteiras, visto que ela vem sendo paulatinamente incorporada pela caótica tábua de valores do ocidente, transmutando as já referidas tradições da cultura judaico-cristãocidental, tanto que diversos preceitos do budismo têm sido adotados por consultores em gestão empresarial no intento de que as corporações do novo milênio não pautem seu crescimento na destruição dos recursos naturais, na avareza e na avidez que estão na base dos problemas ambientais ora enfrentados.

O ecocentrismo propõe, portanto, muito mais do que uma mudança de paradigmas de cunho filosófico-ideológico, mas intenciona por em pauta ações concretas no mundo jurídico e empresarial destinadas a favorecer o equilíbrio e a sustentabilidade das matrizes ambientais. Assim, segundo pontua Shrivastava (1995, p. 131).

Os objetivos empresariais transcenderiam os aspectos mensuráveis de emprego de fatores de produção para a produção de bens/serviços para o mercado, passando a ser uma forma de organização de produção que concilie os interesses do indivíduo, da sociedade e da natureza (...), balanceando as dimensões econômicas, sociais e ambientais da empresa em níveis éticos mínimos, a responsabilidade social corporativa passaria a ser adotada em sua vertente normativa.

Como exemplo do que foi mencionado, cabe a transcrição do quadro em que o mesmo Shrivastava estabelece as distinções entre a gestão empresarial tradicional (Antropocêntrica) e a gestão Ecocêntrica: 


\begin{tabular}{|c|c|c|}
\hline & $\begin{array}{l}\text { GESTÃO TRADICIONAL } \\
\text { (ANTROPOCÊNTRICA) }\end{array}$ & $\begin{array}{c}\text { GESTÃO } \\
\text { ECOCÊNTRICA }\end{array}$ \\
\hline Objetivos & $\begin{array}{c}\text { Crescimento econômico e } \\
\text { lucros. } \\
\text { Riqueza dos acionistas }\end{array}$ & $\begin{array}{c}\text { Sustentabilidade e } \\
\text { qualidade de vida. } \\
\text { Bem-estar do conjunto de } \\
\text { stakeholders. }\end{array}$ \\
\hline Valores & $\begin{array}{l}\text { Antropocêntrico. } \\
\text { Conhecimento racional } \\
\text { Valores patriarcais. }\end{array}$ & $\begin{array}{c}\text { Biocêntrico ou } \\
\text { ecocêntrico. } \\
\text { Intuição e compreensão. } \\
\text { Valores femininos pós- } \\
\text { patriarcais. }\end{array}$ \\
\hline Produtos & $\begin{array}{c}\text { Desenhado para função, estilo } \\
\text { e preço. } \\
\text { Desperdício de embalagens. }\end{array}$ & $\begin{array}{c}\text { Desenhado para o } \\
\text { ambiente. } \\
\text { Embalagens não } \\
\text { agressivas ao ambiente. }\end{array}$ \\
\hline $\begin{array}{l}\text { Sistema } \\
\text { de produção }\end{array}$ & $\begin{array}{l}\text { Intensivo em energia e } \\
\text { recursos. } \\
\text { Eficiência técnica. }\end{array}$ & $\begin{array}{l}\text { Baixo uso de energia e } \\
\text { recursos. } \\
\text { Eficiência ambiental. }\end{array}$ \\
\hline Organização & $\begin{array}{c}\text { Estrutura hierárquica. } \\
\text { Processo decisório autoritário. } \\
\text { Autoridade centralizada. } \\
\text { Altos diferenciais de renda. }\end{array}$ & $\begin{array}{c}\text { Estrutura não hierárquica. } \\
\text { Processo decisório } \\
\text { participativo. } \\
\text { Autoridade } \\
\text { descentralizada. } \\
\text { Baixos diferenciais de } \\
\text { renda. } \\
\end{array}$ \\
\hline Ambiente & $\begin{array}{c}\text { Dominação sobre a natureza. } \\
\text { Ambiente gerenciado como } \\
\text { recurso. } \\
\text { Poluição e lixo são } \\
\text { externalidades. }\end{array}$ & $\begin{array}{l}\text { Harmonia com a } \\
\text { natureza. } \\
\text { Recursos tidos como } \\
\text { estritamente finitos. } \\
\text { Eliminação/gestão de } \\
\text { poluição e lixo. }\end{array}$ \\
\hline
\end{tabular}

Incumbe-nos, porém, ponderar que o propósito da cosmovisão ecocêntrica não é propagado em tom tão uníssono como pode parecer, inexistindo uma unidade doutrinária de fato, já que o ecocentrismo comporta diversas vertentes (correntes 
e subcorrentes), a exemplo das que aparecem na classificação de Herculano (1992), que destaca as seguintes: Alternativa; Neomalthusiana; Zerista; Ecologista Social; Eco-tecnicista; e Marxista.

Entre tais correntes há importantes variáveis conceituais que, a rigor, mereceriam maior aprofundamento. Entretanto, por questões de foco epistemológico, o presente trabalho ateve-se à análise dos preceitos mais gerais do ecocentrismo (que, a nosso ver, confere à concepção ecocentrista uma comparação bastante exitosa em relação ao antropocentrismo).

Por outro lado, faz-se imperioso abordar a vertente mais fundamentalista do ecocentrismo (ecologismo profundo), posto que, conforme já foi dito nas linhas introdutórias deste artigo, o escopo presente também é destacar os riscos potenciais que as acepções extremistas (quer sejam de cunho antropocentrista ou ecocentrista) podem representar.

Uma faceta ortodoxa do ecocentrismo pode muito bem ser sintetizada pela formulação de Diogo de Freitas do Amaral, apud Fiorillo (2002, p. 18):

Já não é mais possível considerar a proteção da natureza como um objetivo decretado pelo Homem em benefício exclusivo do próprio homem. A natureza tem que ser protegida também em função dela mesma, como valor em si, e não apenas como um objeto útil ao Homem (...). A natureza carece de uma proteção pelos valores que ela representa em si mesma, proteção que, muitas vezes, terá de ser dirigida contra o próprio homem. 
Veja-se que a acepção supra transcrita admite que a ação protetiva ao ambiente ocorra, inclusive, em face do próprio Homem, razão pela qual é possível afirmar que ela se aproxima da bandeira erigida pelo ecologismo profundo ou ortodoxo/ fundamentalista que conferem direitos e interesses morais a todas as espécies não humanas e até a componentes abióticas do ambiente, percebendo-se o ser humano moderno como inerentemente desajustado às leis da natureza, e o humano tradicional, aos moldes do "bom selvagem" rousseauniano (NEESS, 1973).

É inconteste que a defesa inflexível da bandeira ecocêntrica também pode levar a extremos muito danosos, pois contempla certo antiprogressismo, em cuja natureza, por possuir valor intrínseco, teria sua proteção assegurada independentemente de qualquer benefício e/ou malefício para o ser humano.

Por conseguinte, faz-se apropriado partir do princípio de que é necessário proceder a avanços cautelosos, progressivos, em direção à nova realidade ecológica, sem abandonar radicalmente o realismo pragmático da sociedade hodierna.

Isto porque se deve reconhecer que a harmonização do ser humano com a natureza não pode ocorrer de forma independente da harmonização das relações sociais. Não parece razoável, portanto, estabelecer uma linha fronteiriça separando, na prática, o antropocentrismo do ecocentrismo, já que há interfaces que se imbricam.

Tanto é assim que há classificações que visualizam outras teorias intermediárias, tais como o expansionismo moral 
(em que não se considera a natureza, mas apenas a fauna com valor intrínseco) e o holismo relutante (que advoga a idéia da teia da vida, das conexões estabelecidas entre os seres vivos que compõem a biodiversidade, mas ainda manifesta traços antropocêntricos, pois argumenta que se um dos elos da teia da vida for rompido, a espécie humana será aniquilada).

\section{CONSIDERAÇÕES FINAIS}

Conforme aqui abordado, o direito ambiental contemporâneo está a caminhar no sentido da superação do modelo clássico da tradição judaico-cristã-ocidental em cujo Homem se estabelece, artificiosamente, como o centro gravitacional do universo e como razão essencial para a existência de todas as demais formas de "vida inferior". Resta inequívoco que essa superação do antropocentrismo faz-se essencial para que se possa estancar o grave processo degradatório atualmente em curso, visando a oportunizar uma convivência harmoniosa, respeitosa e sadia entre todas as formas de vida existentes sobre o Planeta.

Já nem se faz necessário pormenorizar as mazelas ambientais causadas pela visão antropocêntrica de mundo, bastando dizer, para exemplificar, que foi o antropocentrismo entendido ao limite que levou a China a pretender exterminar todas as aves para defender as colheitas de arroz (com resultados, como é sabido, desastrosos), sendo também essa concepção deturpada de mundo a responsável pela destruição de grande 
parte das florestas tropicais do Planeta (e de biomas inteiros) para cederem lugar à grandes áreas de pecuária extensiva. Aliás, exemplos assim seriam possíveis quase até ao infinito.

Assim sendo, em clara contraposição ao modelo antropocêntrico, as ciências (naturais e jurídicas) vem se aproximando (ainda que a passos lentos) de uma perspectiva mais abrangente da vida, denominada ecocêntrica, na qual os interesses do mundo natural e dos seres vivos não-humanos são tão importantes como os da nossa própria espécie, atribuindolhes valor intrínseco (desatrelado a qualquer valor instrumental que o homo sapiens possa lhes dar). É o primado da tese do preservacionismo ambiental para o próprio ambiente e não apenas para salvaguardar a "casa" e os "suprimentos" necessários à existência humana.

Essa visão mais holística, sistêmica e altruísta do ambiente natural é sobremaneira salutar à compreensão da real dimensão da causa ambiental. Entretanto, assim como o antropocentrismo "cego" se mostrou desastroso, também é temerário (por ser igualmente danoso) assumir posições extremadas do ecocentrismo, já que o fundamentalismo ecocêntrico desconsidera a necessidade ainda premente de promover o desenvolvimento sócio-econômico de muitas regiões do Planeta, com o que pode estar inadvertidamente condenando populações inteiras à fome e à mendicância perpétua (sobretudo nos países subdesenvolvidos).

Assim, conforme já mencionado nas linhas introdutórias deste artigo, a retórica ambiental fundamentalista mostra-se 
ultrapassada, nociva e letal, além do que, em qualquer campo de análise científica, ressoa um tanto quanto "ingênuo" defender modelos castos, puramente antagônicos e estanques.

Pelo exposto, o presente escrito advoga em favor da idéia de que há que se assumir uma terceira via ambiental, cujo caminho se estabeleça através de "pontes" entre o pensar antropocêntrico e o pensar ecocêntrico, visto que só um modelo conjugado seria capaz de promover uma relação mais equilibrada (de simbiose) entre a humanidade e esse imenso organismo, capaz de se autoregular, apelidado de Gaia.

Há que se estabelecer, portanto, um diálogo entre os saberes dos dois hemisférios, produzindo sociedades cuja promoção da sustentabilidade da teia vital do planeta se constitua como tarefa prioritária.

Portanto, a bem da necessária sustentabilidade do uso dos recursos naturais e por apego ao fundamento científico, o ambientalismo hodierno deve superar definitivamente a visão antropocêntrica de mundo, sem, contudo, se deixar seduzir pelo "canto da sereia" representado pelo mote do ecocêntrismo puro, o que implica em transformação social e na emergência de novas idéias, propiciando a manifestação de um processo que integre e unifique o homem e a natureza, pois, para além das divergências específicas, o que importa é se nos impor uma ética ambiental adequada, visto que, conforme já foi aqui mencionado, na história do pensamento humano os desenvolvimentos mais fecundos ocorrem, de um modo geral, quando duas correntes totalmente distintas se encontram (HEISENBERG, 1989). 


\section{REFERÊNCIAS BIBLIOGRÁFICAS}

BARRETO, Luís S. Ética Ambiental: uma anotação introdutória. Lisboa: Ciência e Vida, 1994.

BECKERT, Cristina; VARANDAS, Maria José. Éticas e Políticas Ambientais. Lisboa: Centro de Filosofia, 2004.

CAPRA, Fritjof. A teia da vida - Uma nova compreensão cientifica dos sistemas vivos. 6 ed. São Paulo: Cultrix, 2001.

CAVALCANTE, Clóvis. Meio ambiente, desenvolvimento sustentável e políticas públicas. São Paulo: Cortez, 1999.

- DÍAZ, Alberto Pardo. La Educación Ambiental como Proyecto. 2 ed. Barcelona: Editorial Horsori, 1995.

FERRY, Luc. A Nova Ordem Ecológica: a árvore, o animal e o homem. Porto: Edições Asa, 1993.

FIORILlo, Celso Antonio Pacheco. Curso de Direito Ambiental Brasileiro. São Paulo: Saraiva, 2002.

HEISENBERG, Werner. Physics and Philosophy. London: Penguin books, 1989.

KISS, Alexandre. Droit international de l'environnement, - 
Paris: Editions A. Pedone, 1989.

LEIS, Hector Ricardo. O labirinto: ensaios sobre ambientalismo e globalização. São Paulo: Gaia, 1996.

MIRANDA, Pontes de. Tratado de Direito Privado. V. I, São Paulo: Borsoi, 1970.

NAESS, Arne. Ecology, community and lifestyle. Cambridge: University Press, 1989.

NICKEL, James; VIOLA, Eduardo. Integrando a defesa dos direitos humanos e do meio ambiente. São Paulo: Lições do Brasil, 1994.

REALE, Miguel. Primado dos valores antropológicos. Disponível em: <http://www.miguelreale.com.br> Acesso: 01 out. 2009.

SHRIVASTAVA, Paul. Ecocentric Management for a Risk Society. Academy of Management Review, v. 20, n.1, jan/1995.

SOROMENHO-MARQUES, Viriato. O Futuro Frágil: os desafios da crise global do ambiente. Coimbra: Mem Martins, 1998.

, Ecologia e Ideologia. Lisboa: J. Rebelo, 
Livros e Leituras, 1999.

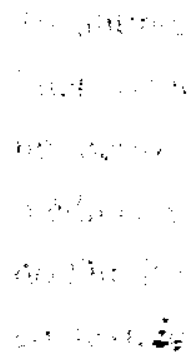

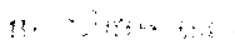

$: \forall$

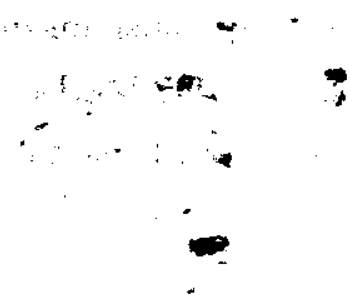

s.

Revista Esmat, Palmas, Ano 3, ñ 2, pag. 261 a 293 - jan/dez, 2011

$\checkmark$

293 